\title{
Perancangan Aplikasi Penentuan Produksi Karet Pada PTPN 3 Kebun Sei Silau Dengan Menggunakan Metode Fuzzy Mamdani
}

\author{
Wanayumini ${ }^{1}$, Devy Pratiwi ${ }^{2}$ \\ 1,2,3 Teknik Informatika, Universitas Asahan \\ Jalan Jendral Ahmad Yani, Kisaran Sumatera Utara

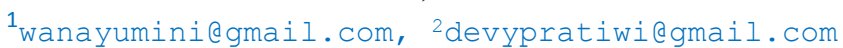

\begin{abstract}
Abstrak - Aplikasi web ini memudahkan admin dalam menangani produksi karet tanpa melakukan tester secara manual lagi. Produksi karet yang baik berdasarkan fuzzy mamdani adalah :Suhu panas dengan nilai $\mathbf{- 0 . 6}^{\circ}$, dengan kondisi tetesan karet yang baik untuk proses produksi. Kelembaban Udara kering dengan nilai $\mathbf{- 0 . 4 \%}$, dengan kondisi tetesan karet yang baik untuk proses produksi. Intensitas Cahaya gelap dengan nilai 0, kondisi tetesan karet yang baik untuk proses produksi. Sistem pendukung keputusan sistem yang menentukan sebuah keputusan untuk memanajemen dan menganalisa pekerjaan secara jelas.Ada beberapa hal yang melemahkan daya saing produksi karet diantaranya adalah dalam pengolahan karet masih dilakukan secara sederhana atau manual, dengan penerapan Metode Fuzzy Mamdani diharapkan dapat meningkatkan produksi karet.
\end{abstract}

Kata kunci - Karet, Sistem Pendukung Keputusan, Metode Fuzzy Mamdani

\section{PENDAHULUAN}

Peningkatan produksi karet di PTPN 3 Kebun Sei Silau masih terhambat oleh mutu karet yang dihasilkan, sehingga mempengaruhi pengembangan produksi akhir karet. Ada beberapa hal yang melemahkan daya saing produksi karet diantaranya adalah dalam pengolahan karet masih dilakukan secara sederhana atau manual, dengan penerapan Metode Fuzzy Mamdani diharapkan dapat meningkatkan produksi karet.

\section{LANDASAN TEORI}

\section{A. Sistem Pendukung Keputusan}

Sistem pendukung keputusan adalah sistem yang menentukan sebuah keputusan untuk memanajemen dan menganalisa pekerjaan secara efektif.

Menurut Heliza Rahamania Hatta, dkk (2016) Sistem Pendukung Keputusan (SPK) merupakan suatu penerapan sistem informasi yang ditujukan untuk membantu pimpinan dalam proses pengambilan keputusan. Sistem pendukung keputusan menggabungkan kemampuan komputer dalam pelayanan interaktif dengan pengolahan atau pemanipulasi data yang memanfaatkan model atau aturan penyelesaian yang tidak terstruktur. Sistem Pendukung Keputusan dimaksudkan menjadi alat bantu bagi para pengambil keputusan untuk memperluas kapabilitas mereka, namun tidak untuk menggantikan penilaian mereka.

\section{B. Himpunan Fuzzy}

Menurut Triyanto Pangaribowo, (2015) Himpunan fuzzy merupakan suatu group yang mewakili suatu kondisi atau keadaan tertentu dalam suatu variable fuzzy. Pada himpunan fuzzy nilai keanggotaan terletak pada rentang 0 sampai 1 . Apabila $\mathrm{x}$ memiliki nilai keanggotaan fuzzy $\mu \mathrm{A}[\mathrm{x}]=0$ berarti $\mathrm{x}$ tidak menjadi anggota himpunan $\mathrm{A}$, demikian pula apabila $\mathrm{x}$ memiliki nilai keanggotaan fuzzy $\mu \mathrm{A}[\mathrm{x}]=1$ berarti $\mathrm{x}$ menjadi anggota penuh pada himpunan $\mathrm{A}$.

\section{Karet}

Karet adalah karet alam yang dideres hingga mengeluarkan getah yang secara alamiah dan secara kimia dapat menggumpal menjadi warna putih yang berasal dari getah pohon.

Menurut Sabarman Damanik tanaman karet (Hevea brasiliensis) merupakan tanaman perkebunan yang penting baik dalam konteks ekonomi masyarakat maupun sumber penghasil devisa non migas bagi negara. Tanaman karet berasal dari daerah tropika lembah Amazon Brazilia dengan curah hujan 2000$3000 \mathrm{~mm} /$ tahun dan hari hujan antara 120- 170 hari/tahun (Sutardi, 1981).

D. Web

Menurut Muhammad Yasin Simargolang (2017) Web scripting adalah jenis script yang kita tambahkan (embedded) pada halaman web yang sebelumnya hanya disusun dengan sintaks HTML. Penambahan script ini mempunyai tujuan tertentu. Misalnya untuk menambahkan informasi jam saat itu, tanggal hari itu, menu yang dinamis (seperti pull down menu), kontrol terhadap sebuah window, animasi sederhana, maupun untuk validasi form. Salah satu script sisi klien yang sering digunakan adalah Javascript.

\section{A. Rancangan Penelitian \\ Untuk menyusun tugas akhir ini, adapun} dilakukan penerapan rancangan penelitian dalam memperoleh data-data yang dibutuhkan sehingga penyusun dalam penelitian ini dapat di selesaikan dengan baik dan sistematis.

Dalam rancangan penelitian yang penulis buat terdiri dari studi pustaka, analisis, desain, implementasi dan evaluasi.

Untuk lebih jelasnya, kerangka rancangan penelitian dapat dilihat pada gambar 3.1. 


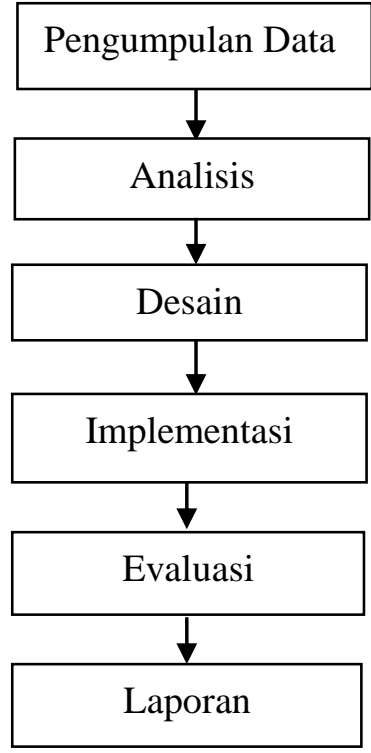

Gambar 1 Rancangan Penelitian

\section{B. Objek Penelitian}

Objek yang dijadikan penelitian adalah tentang system informasi data Perancangan Aplikasi Penentuan Produksi Karet Pada PTPN 3 Kebun Sei Silau Dengan Menggunakan Metode Fuzzy Mamdani digunakan sebagai pendukung untuk melakukan penilaian di Intansi terkait.

\section{ANALISIS DAN PEMBAHASAN}

\section{A. Analisa Masalah}

PTPN 3 Kebun Sei Silau merupakan salah satu BUMN yang bergerak di bidang usaha perkebunan, pengolahan dan pemasaran hasil karet terbesar di Sumatera. PTPN 3 Kebun Sei Silau juga merupakan salah satu pemasok getah karet terbesar di sejumlah pabrik ban bermerek internasioal seperti Bridgestone, Good Year, Firestone, dan Han Kook. Berdasarkan identifikasi masalah dapat di tentukan produksi karet pada PTPN 3 Kebun Sei Silau :

1. Masih menggunakan cara perhitungan konvensional (perhitungan manual).

2. Membutuhkan waktu yang relatif lama.

3. Kemudian PTPN 3 juga belum memanfaatkan suatu system pendukung keputusan.

4. Teknologi system informasi sehingga dapat menentukan produksi karet secara mudah dan cepat.

Berdasarkan permasalahan tersebut penulis mengusulkan:

1. Suatu system pendukung keputusan yang dapat menentukan dan mempercepat proses penentuan produksi karet pada PTPN 3 Kebun Sei Silau.
2. Metode system pendukung keputusan yang digunakan adalah metode dari cabang bidang ilmu Artificial Intelegence (kecerdasan buatan) yaitu metode Fuzzy Mamdani. Metode ini dipilih karena memiliki sifat yang sangat fleksibel dan tolerasi terhadap data yang ada.

Metode Fuzzy Mamdani juga merupakan metode yang sangat sederhana karena bersifat intuitif, mencakup bidang yang luas, sesuai dengan proses input informasi manusia dan tidak memerlukan persamaan matematika yang rumit. Kelebihan dan sifat dari metode Fuzzy Mamdani tersebut cocok untuk menyelesaikan permasalahan penentuan produksi karet pada PTPN 3 Kebun Sei Silau.

\section{B. $\quad$ Penerapan Metode Fuzzy Mamdani}

Sebelum menerapkan metode Fuzzy

Mamdani ke dalam studi kasus penentuan produksi karet pada PTPN 3 Kebun Sei Silau, terlebih dahulu harus ditentukan apa saja yang akan menjadi kebutuhan dalam metode Fuzzy Mamdani, antara lain:

1. Pembentukan Himpunan Fuzzy (Fuzzifikasi)

Variabel input dan output diambil dari setiap criteria dalam menentukan produksi karet. Apabila variable telah ditentukan maka proses selanjutnya adalah menentukan himpunan fuzzy sesuai masing-masing variabel. Adapun variable input fuzzy diambil dari kriteria-kriteria dalam menentukan kualitas tanaman karet dapat dilihat pada tabel 4.1 berikut ini :

TABEL 1

VARIABEL FUZZY

\begin{tabular}{|l|l|}
\hline Variabel \\
\hline Linguistik & Numerik \\
\hline Suhu Dingin & 23 \\
\hline Suhu Normal & 28 \\
\hline Suhu Panas & 33 \\
\hline Kelembaban Udara Basah & 60 \\
\hline Kelembaban Udara Lembab & 65 \\
\hline Kelembaban Udara Kering & 70 \\
\hline Intensitas Cahaya Gelap & 20 \\
\hline Intensitas Cahaya Redup & 30 \\
\hline Intensitas Cahaya Terang & 40 \\
\hline
\end{tabular}

2. Fungsi Keanggotaan

Adapun fungsi keanggotaan dari kriteria-kriteria diatas antara lain:

a. Suhu

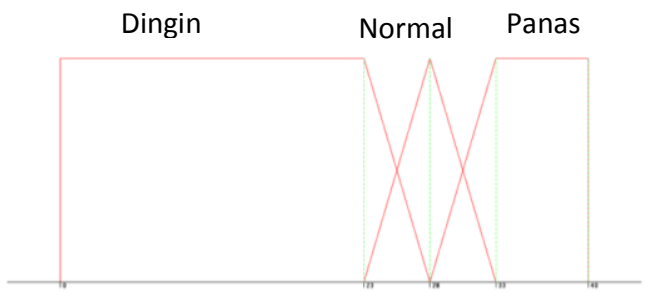

Gambar 2. Fungsi Keanggotaan Suhu 
$\mu$ suhu dingin $=1 ; \quad x \leq 23$

$$
\begin{array}{ll}
\frac{28-x}{28-23} & 23 \leq x \geq 28 \\
0 ; & x \geq 28
\end{array}
$$

$\mu$ suhu normal $=0$;

$$
\begin{array}{cl}
\frac{x-23}{28-23} & x \leq 23 \text { atau } x \geq 33 \\
\frac{33-x}{33-28} & 23 \leq x \leq 33 \\
1 ; & 28 \leq x \leq 33
\end{array}
$$

$$
\mu \text { suhu panas }=\frac{x-28}{33-28} \quad \begin{array}{ll}
x \leq 28 \\
1 & x \leq x \leq 33 \\
2 & x=3
\end{array}
$$$$
2
$$

Hasil dari variable suhu :

$$
\begin{aligned}
& \mu \text { suhu dingin }=\frac{28-x}{28-23}=\frac{28-25}{28-23}=0,6 \\
& \mu \text { suhu normal }=\frac{33-x}{33-28}=\frac{33-2}{33-28}=1,6 \\
& \mu \text { suhu panas }=\frac{x-28}{33-28}=\frac{25-28}{33-28}=-0,6
\end{aligned}
$$

b. Kelembaban Udara

Basah

Lembab Kering

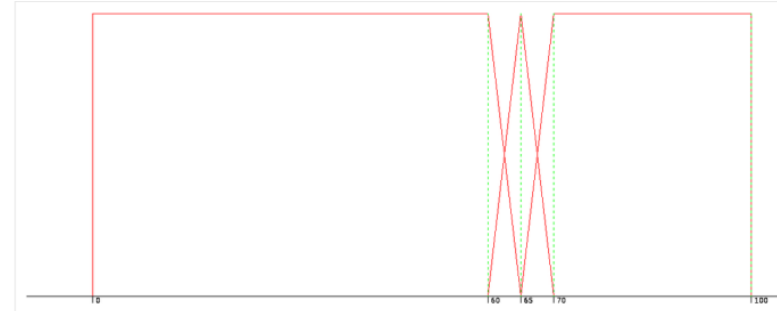

Gambar 3. Fungsi Keanggotaan Kelembaban Udara

$\mu \mathrm{k}$. udara basah $=1$;

$$
\mathrm{y} \leq 65
$$

$$
\begin{array}{ll}
\frac{65-y}{65-60} & 60 \leq y \leq 65 \\
0 ; & y \geq 65
\end{array}
$$

$\mu \mathrm{k}$. udara lembab $=\mathrm{y}-60 \quad \mathrm{y} \leq 60$ atau $\mathrm{y} \geq 70$

$$
\begin{array}{lc}
\frac{65-60}{70-y} & 60 \leq y \leq 70 \\
\frac{70-65}{0 ;} & 65 \leq y \leq 70
\end{array}
$$

$\mu$ k. udara kering $=\mathrm{y}-65 \mathrm{y} \leq 65$

$$
\begin{array}{ll}
70-65 & 65 \leq y \leq 70 \\
1 ; & y \geq 70
\end{array}
$$

Hasil dari variable kelembaban udara : $\mu \mathrm{k}$. udara basah $=65-\mathrm{y}=65-63$

$$
\overline{65-60} \quad \overline{65-60}
$$

$$
=0,4
$$

$\mu$ k.udara lembab $=\frac{70-y}{70-65}=\frac{70-63}{70-65}$

$$
=1,4
$$

$\mu$ k.udara kering $=\frac{y-65}{70-65}=\frac{63-65}{70-6}$ c. Intensitas Cahaya

Gelap Redup Terang

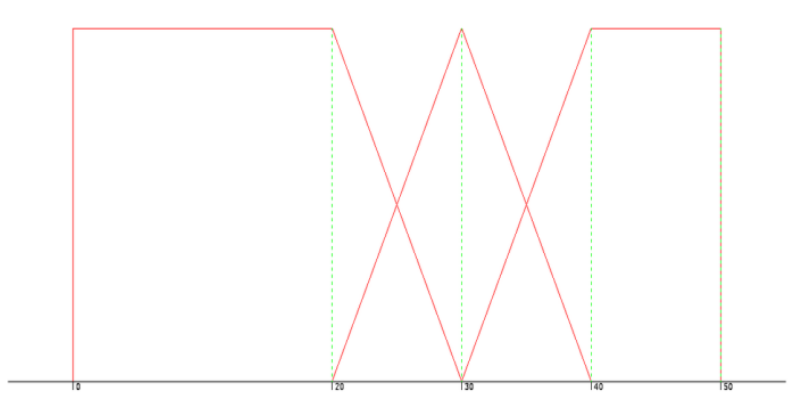

Gambar 4. Fungsi Keanggotaan Kriteria Intensitas Cahaya

$\mu$ cahaya gelap $=1 ; \quad \mathrm{z} \leq 20$

$$
\begin{array}{cc}
\frac{30-\mathrm{z}}{30-20} & 20 \leq \mathrm{y} \leq 30 \\
0 ; & \mathrm{z} \geq 30
\end{array}
$$

$\mu$ cahaya redup $=\frac{\mathrm{z}-20}{30-20} \quad \mathrm{z} \leq 20$ atau $\mathrm{z} \geq 40$

$$
\begin{array}{lc}
\frac{40-\mathrm{z}}{40-30} & 20 \leq \mathrm{z} \leq 40 \\
0 ; & 30 \leq \mathrm{z} \leq 40 \\
=\frac{\mathrm{z}-30}{40-30} & \mathrm{z} \leq 30 \\
1 ; & 30 \leq \mathrm{z} \leq 40 \\
1 ; & \mathrm{z} \geq 40
\end{array}
$$

$\mu$ cahaya terang $=\underline{\mathrm{z}-30} \quad \mathrm{z} \leq 30$

\section{Pembentukan Rule}

Basis aturan-aturan dalam menentukan produksi tanaman karet digunakan fungsi Min. Setelah tahapan fuzzifikasi akan dilakukan pembentukan rule base sebanyak 27 rule, yaitu: Adapun aturan yang didapatkan adalah sebagai berikut :

TABEL 2

ATURAN-ATURAN FUZZY

\begin{tabular}{|l|l|l|l|}
\hline No Aturan & Suhu & $\begin{array}{l}\text { Kelembaban } \\
\text { Udara }\end{array}$ & $\begin{array}{l}\text { Intensitas } \\
\text { Cahaya }\end{array}$ \\
\hline 1 & Dingin & Basah & Gelap \\
\hline 2 & Dingin & Lembab & Redup \\
\hline 3 & Dingin & Kering & Terang \\
\hline 4 & Normal & Basah & Gelap \\
\hline 5 & Normal & Lembab & Redup \\
\hline 6 & Normal & Kering & Terang \\
\hline 7 & Panas & Basah & Gelap \\
\hline 8 & Panas & Lembab & Redup \\
\hline 9 & Panas & Kering & Terang \\
\hline
\end{tabular}

4. Fungsi Implikasi

Setelah melakukan pembentukan aturan maka akan dilakukan pembentukan aplikasi fungsi implikasi. Pada model mamdani, fungsi implikasi yang digunakan adalah operator $M I N$, yang berarti tingkat keanggotaan yang didapat sebagai konsekuen dari proses ini adalah nilai minimum dari variabelvariabel produksi karet.

\section{Penegasan (Defuzzifikasi)}


Input dari proses defuzzifikasi adalah himpunan fuzzy yang diperoleh dari komposisi aturan fuzzy, sedangkan output yang dihasilkan merupakan suatu bilangan tegas pada domain himpunan fuzzy tersebut. Sehingga jika kita memberikan suatu himpunan fuzzy dalam range tertentu, maka harus diambil suatu nilai crisp tertentu sebagai output. Dalam penelitian ini defuzzifikasi yang digunakan untuk menentukan nilai produksi karet adalah metode centroid. Metode centroid digunakan untuk menghasilkan solusi crisp dengan mengambil titik pusat $\left(\mathrm{z}^{*}\right)$ daerah fuzzy.fungsi keanggotaan dan rule yang telah ditentukan sebelumnya dalam menentukan produksi karet :

(R1) IF SUHU DINGIN AND KELEMBABAN UDARA BASAH THEN INTENSITAS CAHAYA GELAP

$$
\begin{aligned}
\alpha_{1} & =\operatorname{Min}(0.6:-0.4) \\
& =-0,4
\end{aligned}
$$

(R2) IF SUHU DINGIN AND KELEMBABAN UDARA LEMBAB THEN INTENSITAS CAHAYA REDUP

$$
\begin{aligned}
\alpha_{2} & =\operatorname{Min}(0.6: 1.4) \\
& =0,6
\end{aligned}
$$

(R3) IF SUHU DINGIN AND KELEMBABAN UDARA KERING THEN INTENSITAS CAHAYA TERANG

$$
\alpha_{3}=\operatorname{Min}(0.6:-0.4)
$$$$
=-0,4
$$

(R4) IF SUHU NORMAL AND KELEMBABAN UDARA BASAH THEN INTENSITAS CAHAYA GELAP

$$
\alpha_{4}=\operatorname{Min}(1.6: 0.4)
$$$$
=0,4
$$

(R5) IF SUHU NORMAL AND KELEMBABAN UDARA LEMBAB THEN INTENSITAS CAHAYA REDUP

$$
\begin{aligned}
\alpha_{5} & =\operatorname{Min}(1.6: 1.4) \\
& =1,4
\end{aligned}
$$

(R6) IF SUHU NORMAL AND KELEMBABAN UDARA KERING THEN INTENSITAS CAHAYA TERANG

$$
\begin{aligned}
\alpha_{6} & =\operatorname{Min}(1.6:-0.4) \\
& =-0,4
\end{aligned}
$$

(R7) IF SUHU PANAS AND KELEMBABAN UDARA BASAH THEN INTENSITAS CAHAYA GELAP

$$
\alpha_{7}=\operatorname{Min}(-0.6: 0.4)
$$$$
=0,4
$$

(R8) IF SUHU PANAS AND KELEMBABAN UDARA LEMBAB THEN INTENSITAS CAHAYA REDUP

$$
\begin{aligned}
\alpha_{8} & =\operatorname{Min}(-0.6: 1.4) \\
& =-0,6
\end{aligned}
$$

(R9) IF SUHU PANAS AND KELEMBABAN UDARA KERING THEN INTENSITAS CAHAYA TERANG

$$
\begin{aligned}
\alpha_{9} & =\operatorname{Min}(-0.6:-0.4) \\
& =-0,4
\end{aligned}
$$

Maka :

Intensitas cahaya gelap $=0$

$$
\begin{aligned}
& \text { Intensitas cahaya redup }=\frac{40-\mathrm{z}}{40-30} \quad=0,4 \\
& \begin{array}{l}
40-30 \\
40-\mathrm{z}
\end{array} \quad=0,4 \times 10 \\
& 40-z=4 \\
& -\mathrm{Z}=4-40 \\
& \mathrm{z}=36 \\
& \text { Intensitas cahaya terang }=\quad \mathrm{Z}-30= \\
& 0.6 \\
& \overline{40-30} \\
& z-30=0,6 \times 10 \\
& \mathrm{z}-30=6 \\
& \mathrm{z}=6+30 \\
& \mathrm{z}=36
\end{aligned}
$$

\section{Implementasi system}
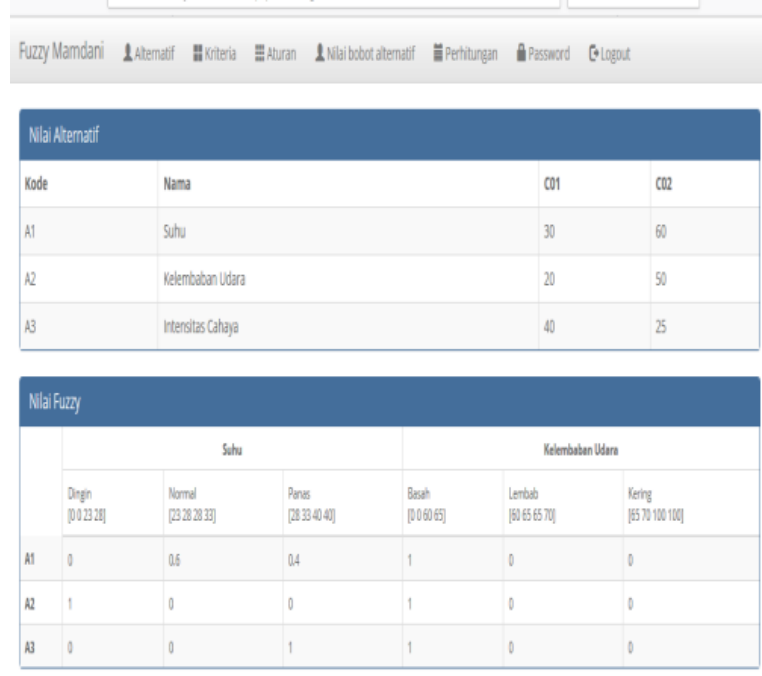

Gambar 5 Tampilan Aturan Fuzzy

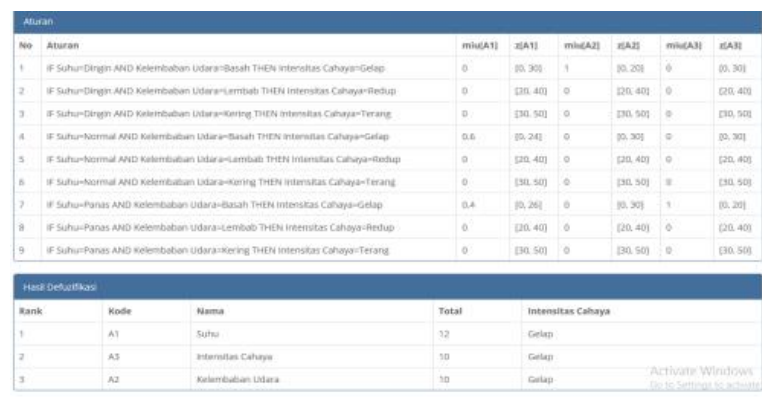

Gambar 6 Tampilan Hasil Fuzzy

\section{PENUTUP}

A. Kesimpulan

Dari hasil Perancangan aplikasi penentuan produksi karet pada PTPN 3 kebun sei silau dengan menggunakan metode fuzzy mamdani, makadapat diambil kesimpulan sebagai berikut :

1. Aplikasi web ini memudahkan admin dalam menangani produksi karet tanpa melakukan tester secara manual lagi. 
2. Produksi karet yang baik berdasarkan fuzzy mamdani adalah :

Suhu panas dengan nilai $-0.6^{\circ}$, dengan kondisi tetesan karet yang baik untuk proses produksi. Yang berarti if(jika) suhu panas and(dan) kelembaban udara lembab then(maka) intensitas cahaya redup

Kelembaban Udara kering dengan nilai $0.4 \%$, dengan kondisi tetesan karet yang baik untuk peroses produksi. If(jika) suhu dingin and(dan) kelembaban udara kering then(maka) intensitas cahaya terang

Intensitas Cahaya gelap dengan nilai 0 , dengan kondisi tetesan karet yang baik untuk peroses produksi.

\section{DAFTAR PUSTAKA}

[1] Heliza Rahamania Hatta et.all. 2016. “ Penerapan Metode Weighted Product Untuk Pemilihan Lokasi Lahan Baru Pemakaman Muslim Dengan Visualisasi Google Maps" TEKNOSI, Vol.02, No. 3

[2] Muhammad Yasin Simargolang, 2017 "Implementasi Kriptografi Rsa Dengan Php", Jurnal Teknologi Informasi (Jurti)Volume 1, Nomor 1

[3] Triyanto Pangaribowo. 2015. “ Perancangan Simulasi Kendali Valve Dengan Algoritma Logika Fuzzy Menggunakan Bahasa Visual Basic", Jurnal Teknologi Elektro, Universitas Mercu Buana, Vol.6 No.2

[4] Sabarman Damanik. 2012. "Pengembangan Karet (Havea brasiliensis) Berkelanjutan Di Indonesia", Perspektif Vol. 11 No. 1. 